\title{
Qualities and practices of professional social work leadership in an interdisciplinary mental health service: an action learning approach
}

\author{
David McNabb \\ Michael Webster
}

\begin{abstract}
Since the mid-1980s, health service restructuring in New Zealand has strengthened managerialism, arguably detracting from professional considerations. Professional leaders without line-management responsibilities have replaced social work departments headed by a professional social worker. An emerging social work contribution to interdisciplinary leadership in mental health settings aims to advance quality of service and fill social work leadership gaps resulting from structural changes created by health policy initiatives. In the context of limited research into these changes, this paper presents an action learning organic approach examining how social work professional leaders implemented Kouzes and Posner's 'exemplary leadership' in a District Health Board. This examination integrates indigenous Māori approaches to leadership with Western models. Findings suggest both caution and optimism about the professional leader role. The paper suggests further research to explore the relationship of professional leadership and clinical governance in public health services.
\end{abstract}

Keywords: professional leadership; exemplary leadership; mental health

\section{Introduction}

This paper reports a group investigation by professional social work leaders of values underpinning their contribution to interdisciplinary mental health services in a restructured District Health Board (DHB) setting in Aotearoa New Zealand. The project explores how the group implemented 'exemplary leadership' (Kouzes and Posner 1995, 2007) in an organic complex environment by examining their views and actions. The referent framework includes a complexity perspective examining organizational change as a cultural phenomenon, conceptually parallel to Trehan and Pedler's (2009) 'process-based leadership', which has emerged in a critical action learning approach in organizational settings. Issues addressed include major opportunities for social work resulting from recent organizational change; the key qualities of effective social work leaders; and the presence and development of these qualities in social work leaders. Future research examining leadership influences in the context of clinical governance, an emerging transnational phenomenon in health management aiming to improve service quality (Moullin 2002), is proposed.

Two crucial elements are noted in what follows. First, the professional leaders in this project were convened, not as an action learning set, but as a focus group. The authors' ex post facto examination of what took place suggested that action learning had in fact occurred and warranted analysis. Second, transcripts of the group's actions deductively drive the analysis 'real-time/real-life action' (Revans 1998, 10).

The paper tells an unfolding story of professional-managerial tensions and structural changes in a complex environment, encompassing the exercise of emergent leadership. The paper's action learning framework affords the authors opportunity to examine a dynamic process reflecting Revans' $(1982,724)$ seminal description of 'learning from [his] actions [I]' as an ongoing 
participant with professional colleagues [WE]; and through professional and academic dissemination shared that learning with 'the wider world [THEY]'. David McNabb is an active member of our professional body, the Aotearoa New Zealand Association of Social Workers (ANZASW) and is also an adjunct academic teacher. In respect of the ANZASW, David and Michael Webster are collaborating in the formation of a Leaders' and Managers' Interest Group seeking to facilitate debate on the tensions between new managerialism - which has profoundly influenced state sector social and health services since the 1980s - and professional social work service delivery. These spheres enable dissemination of the 'I/WE/THEY' paradigm.

David's contribution gives expression to the underpinning notion articulated by Pedler $(2004,3)$ that 'Action learning accords a secondary place to the views and advice of experts and gives primacy to the people who live and must deal with the problems or opportunities in question'. As co-author, Michael edited David's material and provided a setting in which his findings and their practice implications could be demonstrated to a wider audience: a practitioner-academic collaboration.

\section{Literature review}

The project draws on four distinct - but interrelated - fields: action learning; the organizational context for leadership and management, including 'managerialism'; reflective professional practice; and complex, or emergent, organizational leadership and change. A fifth field, clinical governance, awaits future treatment. The authors integrate action learning as a framework to examine the relevant literature in these fields to provide a holistic perspective on the project.

\section{Action learning and systems thinking}

In this paper, the authors contextualise organic systems-orientated social work leadership values and practices to a wider discussion of professional leadership in public sector bureaucratic change (Attwood, Pedler, Pritchard, and Wilkinson 2003). Connections between action learning's characteristic 'questioning insight' (Revans, 1998, 29) and the application by social work leaders of Schön's $(1991,50)$ 'reflection-in-action' are explored in the wider context of organizational 'complex responsive processes' (Stacey and Griffin 2008, 4). Revans' (1998, 30) descriptor of 'the set as the cutting edge of Action Learning' (Revans, is critically applied to the professional social work leadership group in the investigation. The 'unfamiliar problem in a familiar sett ing' [Revans, 1998, 23]) - implementing 'exemplary leadership in Auckland DHB mental health services - is discussed; and how the processes used Revans' 'learning equation' is explored:

$$
\text { L[earning }]=\mathrm{P}[\text { rogrammed knowledge }]+\mathrm{Q}[\text { uestioning insight] }(\text { Revans, 1998, 4) }
$$

The diagnostic learning equation tool enabled analysis of participants' comments by harnessing Morris' $(1991,71)$ notion that 'for Revans, education and training have placed far too much dependence on $\mathrm{P}$, taught by accredited experts, rather than $\mathrm{Q}$... people questioning their own direct experience.' This practitioner-driven project nonetheless drew on the lead author's managerial knowledge as a postgraduate student.

The authors note strikingly similar concepts connecting action learning, social work systems understanding of professional leadership actions in organizations and complexity thinking. The pre-eminence afforded to 'Q', by which the 'professional teacher [should become] a Q-seeking participant ...quite independent of all pre-disposing P knowledge' (Revans, 1998, 11), is reminiscent of underpinning social work approaches to learning, theory and practice. Payne (1997, 3, 13) articulates a 'what works' methodology in his treatment of 'the social construction of social work theory': 
In selecting a 'theory' to use, workers contribute to how social work is constructed, because what they do ... is or becomes social work ... 'Theories' ... must be products of the context in which they arise. (italics in original)

Social work has embraced Jarvis' $(1995,79)$ concept of the 'person-in-social-context' environment, giving rise to constructivist experiential learning. Jarvis $(2004,115)$ argues that 'all knowledge is subjective and ... knowers construct their own knowledge' while emphasizing collaboration as a critical element in that construction. Constructions are hypothetical, subject to the test of experience in a 'problem solving cycle' (Jarvis 2004, 125), related to Kolb's learning cycle (Kolb 1984) and Schön's (1991) 'reflection-in-action'.

\section{Action learning, reflective professional practice and organic complexity leadership}

Schön $(1991,50)$ defines reflection-in-action as a process of '... people and professional practitioners ... turn[ing] thought back on action and on the knowing which is implicit in action' capable of dealing 'with situations of uncertainty, instability, uniqueness and value conflict' (italics added). This is effectively an alternative expression of Revans' $(1998,29)$ articulation of the 'learning equation' context:

There is the need to master the taking of decisions in circumstances of change so violent as to be confusing [which] calls for an ability to pose useful questions when there can be no certainty as to what next might happen. (italics added)

Kolb's $(1984,38)$ definition of experiential learning applies reflection-in-action:

Learning is the process whereby knowledge is created through the transformation of experience. (italics in original)

The organic, or emergent, procedures encapsulated in experiential learning are articulated by Revans $(1991,5)$ in his description of action learning as 'a social process, whereby those who try it learn with and from each other'. Indeed, Kolb's definition, above, is an alternative rendering of Revans' (1998, xix) classic statement that 'there can be no learning with action and no action without learning'. Even a cursory survey of Revans reveals a longstanding organic, emergent thread running through his writings. In a 1959 paper, for example, entitled 'The hospital as an organism', Revans $(1982,123-4)$ argues for a complexity perspective whereby patient care is dependent on the morale of nurses, doctors, managers and service workers. The current project suggests that social workers function in - and understand - the organic complexity that Revans persuasively articulates.

Integration of action learning with systems thinking's 'five keys' (leadership, public learn ing, valuing difference and diversity, meeting differently, follow-through and sticking with it) and organic/emergent organizational perspectives on leadership development and change is coherently presented in Attwood et al. (2003). These authors also critique a 'top down' managerialist change agenda that fails to engage the hearts and minds of the staff tasked to operationalize senior management's 'vision'. In a true-to-life scenario, Attwood and her colleagues (2003, 62) depict workers exiting a 'change and vision' corporate 'hard sell' meeting commenting:

I didn't understand that, did you?

I had a question but I didn't like to ask it. I was afraid of sounding critical.

What's the point of getting involved? They'll do what they want anyway. They always do! 
Deming's (1986) classic prescription to 'drive out fear' to enable change applies to these reactions that sit at the 'closed' rather than 'open' end of a systems process spectrum. Following Attwood et al. $(2003,29)$, the authors propose that applying action learning to systems thinking's five keys creates a platform for the current professional social work leadership project. How might that application occur?

Attwood et al. $(2003,65)$ argue that 'complexity and uncertainty' require strategic-level organizational leaders to tap into perspectives afforded by 'other players in the system'. The professional social work leaders in the current project became these 'other players', applying AL to an 'exemplary leadership' construct in a district health board mental health service. Leadership qualities noted by Attwood et al. (2003, 58-74) apply to the current exemplary leadership project and also strike a chord with social work practice values. Notions of 'humanising servant leadership;' 'holding frameworks' for shared, not imposed, 'mission' by 'appropriate dialogue'; 'diversity' as a source of 'innovation and learning'; holding the dynamic tensions between 'autonomy and direction' and 'listening and forthright' communication modes; 'building a [creative] learning community' informed by 'living' organizational images with indigen ous Māori organic perspectives, e.g., a 'flock of birds', are compellingly pertinent to classic social work values expressed in this project. Indigenous perspectives are further discussed later in this paper.

This leadership discourse is usefully analyzed through Morris' (1991, 76-9) treatment of Revans' 'questioning insight' (' $Q$ ') demonstrated in the de facto action learning set constituted by the professional leaders in the current project. Morris proposes that 'leadership' is not to be equated with 'expertise' - programmed management knowledge ('P'). Instead, harnessing Revans' (1998, 80 ) equation of the action learning set to the 'learning community', Morris $(1991,77)$ evokes the image of a:

... leader engag[ing] others in a fellowship, bringing people together through strong personal ties based on shared values, a clear and accessible vision towards which to work, and a recognition of the contribution that each can make in achieving the common cause. ... Others come to recognize that the outstanding quality of leaders is to empower their fellows to join in taking a lead themselves.

The action set in the current project expressed the qualities articulated by Morris: a partnership working from shared social work values seeking the transition of an 'espoused theory' to develop 'exemplary leadership' to a 'theory-in-use' (Argyris and Schön1974) by empowering leadership that recognizes collegial contributions. This referent framework reflects Rank and Hutchison's $(2000,499)$ definition of social work leadership as 'a process of advocacy and planning whereby an individual practices ethical and humanistic behaviour to motivate others (clients and colleagues) to achieve common goals articulated by a shared vision'.

\section{Project organization context: multidisciplinary teams in mental health}

The establishment in 2001 of 21 District Health Boards as a politically driven, top-down process was the most recent change affecting Mental Health Services (MHS) in New Zealand. Most MHS have moved to a community-based service setting from the previous profession-based departments in hospital settings. Social workers have joined multidisciplinary teams led by managers and clinical leaders from across the health professions (Woodward 2001). Professional leadership, within disciplines, is still evolving and is now largely provided by an advisor for each profession.

Professional leaders are responsible for recruitment, performance management and training of social workers, establishing professional standards, policy, quality improvement relating to social work and the wider organisation, and setting salaries. Other duties remain constant: coordinating supervision, student placements and intern programmes, salary progression procedures, and 
overseeing senior social worker roles. An informal network of health and mental health social work leaders developed in the upper North Island of New Zealand supported the project and supplied participants.

District Health Boards responded to the loss of allied health professional voices at the senior organizational level by establishing allied health structures. The first - the director of allied health position established within the Auckland DHB in 2002 - enabled allied health professions to influence senior management and exercise leadership at the board wide clinical governance process (Mueller and Neads 2005).

\section{Professional leadership}

The exercise of clinical governance in multidisciplinary teams connects with the professional leadership literature in that the emergence of a professional 'voice' (Mueller and Neads, 2005) influences clinical practice in those teams. In the New Zealand context, Matthewson $(2007,38)$ distinguishes professional leadership in mental health social work from line management. His qualitative research suggests that professional leaders experience 'significant ambiguity in the role' but that 'there is opportunity for the exercise of expert power and informal strategic influence.' This analysis draws on leadership complexity theory, which posits that influence does not depend on formal position, arguing that organizations create complex problems not amenable to solutions by top management (Northouse, 2007; Uhl-Bien and Marion, 2008; Yukl, 2010). A complexity approach to professional leadership in the current project enables a referent framework for discussion while also recognizing that the Auckland DHB created formal positions to facilitate the 'professional voice'.

Social work leadership in hospital settings in the USA is examined by Mizrahi and Berger (2001) in the context of changes in the healthcare system. They note minimal literature dealing with social work leadership and share with Matthewson (2007) a distinction between management and leadership:

\footnotetext{
Management is about getting the work done. It is the technical and operational components of the job. Leadership is about setting the direction, standards, and vision for the organization. The personal orientation of the leader, the internal-external environment, professional values, and the political and economic climate all play a role in shaping this vision. (Mizrahi and Berger, 2001, 172)
}

Mizrahi and Berger identify five action-oriented health social work leadership skills: accurate environmental scanning; reengineering your own department; maintaining strengths in your environment; innovating and experimenting; and creating community partnerships. Leadership qualities include passion, optimism, political acumen, an ability to look into the future in shaping priorities, tenacity and a joy for adventure.

The current project aligned participant responses to Kouzes and Posner's $(1995,2007)$ five fundamental practices of exemplary leadership, which fall within the transformational paradigm (for example, Burns 1978; Bennis and Nanus ,1985; Bass and Avolio, 1993). The five behavioural practices are modelling the way, inspiring a shared vision, challenging the process, enabling others to act and encouraging the heart (Kouzes and Posner, 2007, 14-26). These practices gain credibility by being honest, forward looking, inspiring and competent. Leadership is defined as 'the art of mobilising others to want to struggle for shared aspirations' (Kouzes and Posner, 1995, 30). The professional advisory role in MHS suggests a leadership rather than a management role. Most of the research participants did not have management responsibility for social workers. Kouzes and Posner's definition of leadership equates with participants' experience, thus applying action 
learning 'questioning insight' by participants in the context of 'programmed knowledge' (Revans, 1998, 4).

Mizrahi and Berger (2001) also note that a major leadership competency is the ability to manage conflicting demands of consumers, the organisation and staff. They identify paucity of literature examining how leaders manage these pressures and the lack of comparative research of social work leaders across settings and communities. Their research is used comparatively in the discussion below.

\section{Methods}

The project utilised mixed methods in an action learning paradigm case study approach. The integration of practitioner research and academic editing illustrates the objective of action learning to 'write from practice for practice' (Pedler 2004, 5). The unit of analysis (Hussey and Hussey 1997 ) is the implementation of exemplary leadership by social work professional leaders.

Questionnaires were sent to the 16 social work leaders in MHS identified in the 21 District Health Boards. Nine questionnaires were completed and returned. Responses to the questions about the social work leaders themselves and their social work services were largely quantitative in nature. Responses to the other questions about changes, accomplishments, frustrations and obstacles, opportunities, threats and challenges, anticipated changes relating to their social work services and questions on leadership qualities have been grouped and interpreted.

The lead author was also a participant in the project, which was written up as a postgraduate research report. Ethical issues were addressed by the university ethics review process.

\section{How action learning informed the project}

The authors consider that the project, originally described as a focus group, functioned in fact as an action learning set (p. 41, this paper), enabling participants to construct a collegial social work mental health leadership model. The group hereinafter referred to as an action set, numbered seven and essentially met Revans' criteria for set membership of 4-6 (Revans ,1998, 29). The action set met in October 2001. Following O'Hara, Bourner and Webber (2004) as cited in Pedler and Abbott $(2008,188)$, the lead author acted as a facilitator, using such skills as 'questioning, active listening, understanding group process, problem-solving, reflection, understanding learning', which are also requisite social work practice competencies.

Retrospective analysis suggested that critical action learning components present in the project were the 'processes' in the set; the existence of a 'problem' - in this case, an opportunity to create a leadership model; and the skills already identified (Pedler, 2008, 32-61). Revans' (1998) 'characteristic assumptions of action learning' and its 'essential logistics' were also evident. The integration of these elements in the project is now discussed and their connections with social work practice noted.

Pedler (2008) articulates a practical application of action learning in the context of its values and assumptions. The project unconsciously utilized these processes, starting by set members feeling safe to expose their own thinking to colleagues. Affirmative support and questioning challenges potentially leading to action learning's 'questioning insight' - resulted in creative, productive work (Pedler, 2008, 33). Analysing project effectiveness emerged five years later as professional advisors, a new position supporting multidisciplinary professional leaders, were surveyed a year after their initial appointment. Positive findings of supervisors' performance, the role itself and 
benefits accruing to services and allied health professionals were noted (Thorburn, McNabb, and Rook, 2007).

Revans' (1998, 8-9) more philosophical action learning framework suggests that the 'risk imperative' in tackling 'real problems or fertile opportunities' requires exploration of values and beliefs. This quintessential social work practice approach found expression as action learning set participants came to grips with the value-laden construction of professional leadership in a 'real-life' situation (Revans 1998, 10). The egalitarian action learning set of social work leaders added authenticity to the project by virtue of carrying professional responsibility for delivering district health board social work MHS. This was no case study exercise. Interdisciplinary accountability as well as social work professional integrity was on the line. The authors suggest that this process constituted the heart of the action learning project as analyzed after the event.

Revans $(1998,31)$ also argues for 'capacity to ask fresh questions rather than communicate technical knowledge' by using the 'learning equation' $(\mathrm{L}=\mathrm{P}+\mathrm{Q})$, thus implicitly endorsing a social work 'enquiry' methodology recognizing the limits of knowledge and empowering colleague-to-colleague (or indeed worker-client) engagement. Follett's operational power-sharing is a social work managerial value (Graham 1995), contributing to Revans' (1998, 31; cf. Wenger, McDermott, and Snyder 2002) 'learning community'. By operating in this vein, the action learning set integrated a social work ethos with Revans' (1998, 33-35) 'diagnostic questions' and subsequent 'analysis [and] avenues of enquiry'. A loop back to a social work enquiry mode is demonstrated.

\section{Action learning limitations}

Analysis of this project as an ex post facto reconfigured action learning programme produced limitations. These included an inability to hold an iterative process in order to review set members' contributions; a consequent inoperability of Revans' (1998) rollout of 'six sequential phases'; and an effective learning review for action learning set members as distinct from an organizational review using the professional supervisors' influence six years later. Expert 'P' knowledge in the form of Kouzes and Posner's $(1995,2007)$ exemplary leadership practices defined the parameters of action learning set debate to a greater extent than Revans or Pedler would allow. The project might thus be more accurately described as an incipient action learning set.

\section{Results}

Five categories derived from Mizrahi and Berger's (2001) research were used to code responses: the social work profession, inter-professional relationships, the workforce, the organization and resourcing.

Of the nine responses to the question relating to potential future changes to professional leadership role, four were negative, three were mixed or neutral and two were positive. This is in contrast to earlier responses to the question on expected changes over the previous two years, where six respondents were positive, two negative and one mixed. A majority positive response from leaders about the immediate past may suggest potential for a positive future orientation.

Responses from the leaders were aligned with five exemplary leadership practices: challenge the process, inspire a shared vision, enable others to act, model the way and encourage the heart (Kouzes and Posner 1995, 2007). Overall, the leaders presented a mix of caution and optimism about their role and for the future of social work services in mental health. 
The authors have selected two of the five leadership practices to illustrate an action learning analysis of the project.

\section{Analysis of leadership practice}

In the context of Kouzes and Posner's (2007) leadership practices, participants articulated how they exercised leadership of social workers in MHS. Responses from the action set are noted in this section. These included qualities of effective leaders, the qualities participants demonstrated, qualities most desired and general comments about being a leader. The term 'quality' was interpreted broadly by respondents to include experience undertaking specific work:

1. Model the way (Kouzes and Posner 2007, 15). Kouzes and Posner propose that leaders create and model standards of excellence, standing for relentless pursuit and completion of actions to institutionalise professional values and beliefs. Because complex change can be hard to achieve they take small steps to achieve their plans.

2. Inspire a shared vision (Kouzes and Posner, 2007, 16). The leader's vision of what could be translates to inspiring others to share that vision. Leaders must know their constituents and have their interests at heart. Leaders are enthusiastic about their vision and ignite the flame of passion in others.

Participant responses. Action set comments revealed that leaders espouse an empathetic consumer orientation and commitment to professional standards of practice together with passion and enthusiasm. One participant contrasted the institutional advantages of mental health vis-a'-vis medical and other services evidenced by the holistic government strategy for MHS contained in the Blueprint (Mental Health Commission, 1998) and linkage of professional social work to the accreditation standards as a mechanism to focus the organisation.

3. Challenge the process (Kouzes and Posner 2007, 18)

'Challenging the process' is a change-agent function. Leaders analyse their situation, recognise the good ideas of others, seek knowledge and learn from it, take risks, innovate and get new ways adopted. Leaders learn from their successes and their failures. Participants identified historical under-funding of mental health vis-a'-vis that of general health services and budgetary transfers from mental to general health as an issue.

Participants with trans-departmental experience could compare processes 'that worked' or otherwise in distinct settings. Understanding the political climate within the organisational context was a key attribute for leadership of social work as a profession within this setting.

4. Enabling others to act (Kouzes and Posner 2007, 20)

The fourth leadership practice encourages ownership of required team effort among constituents. Exemplary leaders enlist workers' support and assistance and enable them to act via development of trust, which facilitates effective teamwork.

Participant response. Action set comments identified the creation of a 'psychological contract' operating by peer mentoring 'buddy' system for new staff (Payne, Culbertson, Boswell, and Barger, 2008) as central to empowering leadership. A culture of development is formed by opening informal and organizational leadership opportunities, stretching professionals by encouraging postgraduate study and practising situational leadership: all team members have skills to lead at different times and in different situations (Blanchard, Zigarmi, and Nelson, 1993). A leader's task is to draw these out, encourage and provide opportunities for development personally and professionally.

5. Encourage the heart (Kouzes and Posner, 2007, 21) Leaders encourage perseverance in others in adversity, tiredness and frustration by recognising constituents' contributions and goal achievement. The rewards of team efforts are shared amongst members who feel well regarded or even loved by their leader. 
Participant responses. Action set discussion on the problems associated with a new leadership role led to suggestions for a way forward. Ideas advanced included informal conversations with experienced leaders, involvement with the inter-regional social work leaders' forum, accessing good information, supervision and ongoing support.

Another leader drew on the support of colleagues from allied health and events in their wider networks. Leaders noted the importance of humour and support for staff and consumers. The group enthusiastically advanced support for new leaders. Some participants encouraged the lead author's research and noted its contribution to improving recognition of the professional leadership role in mental health.

\section{Discussion}

Three essential themes emerge from the project:

- tensions and connections between emergent leadership and formal organization structure, power and authority;

- $\quad$ complex adaptive change management; and

- the integrative potential of clinical governance in advancing recognition of semi-professions (Etzioni 1969) in a health setting.

\section{Essential tensions}

The authors propose that the source of the tensions identified in the project is found in three factors: managerialism as a pervasive influence in health reforms; complexity as an explanation for emergent leadership; and the clinical governance model as a potentially integrative influence to reconcile the first two. For reasons of space, examination of clinical governance awaits future treatment.

\section{Managerialism, organic change and indigenous approaches}

Managerialism as a philosophical perspective per se hardly featured in action set discussion. Its absence may be explained by the nature of the group as professional leaders who saw their influence as organic, if only because they did not hold significant line management responsibilities. Equally, the authors suggest that professionals prioritise commitment to ethical values, to colleagues and consumers over organizational mandates. Professional leaders discount managerialist demands for performance planning in which individuals are measured by organization outcomes, a never-ending machine-like appetite for information and the artificial world of 'systematic top-down strategies and procedures ... imposed on ... complex and interconnected systems' (Attwood et al. 2003, 21). Instead, they conceptualise the organization as an organism, reflecting Morgan's (1997) living image emerging in Western management thinking and indigenous approaches.

In New Zealand, ideas from indigenous thinking have begun to both augment and challenge Western management. Indigenous insights, holistic and spiritual components become part of the pattern that makes up the whole. Tipu Ake (Te Whaiti Nui-a-Toi 2001) is an example of a 'living' organization, better described as an 'organism', illustrating Maori thinking. The familiar chain of command organizational chart accountabilities have been replaced by a living tree, a paradigm alien to notions of machine or professional bureaucracy (Mintzberg 1989). Integration of these indigenous notions - which pre-date European colonization - is emerging in professional leadership thinking in public sector organizations in New Zealand. Management theorists and practitioners, generally educated in Western models, are discovering this approach. An example is the evocative title of de Geus' (1999) 'The Living Company'. Peter Senge's foreword to the book 
captures de Geus' thinking:

At the heart of this book is a simple question with sweeping implications: what if we thought about a company as a living being? This raises the obvious question: what is the alternative view of a company if we do not see it as a living being? The alternative view is to see a company as a machine for making money. The contrast between these two views ... illuminates a host of core assumptions about management and organizations. (De Geus, 1999, 2)

Morgan (1997) makes a connection between 'brain' and the 'learning organization' (Senge, 1990) and 'organism' and the human relations management models pioneered by such thinkers and researchers as Mayo, Herzberg, Argyris, Schön and Parker Follett (Morgan, 1997, 35-36, 88). Morgan $(1997,34)$ evokes biological images in describing the movement away from Taylorist scientific management:

Organizational theory has become a kind of biology in which the distinctions and relations among molecules, cells, complex organisms, species, and ecology are paralleled in those between individuals, groups, organizations, populations (species) of organizations, and their social ecology. (italic in original)

The depiction of the management of organizations as reflecting indigenous 'living organism' metaphors enjoys conceptual links with Gregory's (2001) distinction between 'mechanistic' and 'organic paradigms'. He proposes that 'state sector reforms [in New Zealand] were impelled by an essentially mechanistic ... interpretation of governmental institutions' (Gregory, 2001, 235, italics in original). In metaphorical language, Gregory draws attention to the mechanistic pictures of 'machinery of government', 'levers of control', and 'policy settings', contrasting the 'organic perspective' as:

... focus[ing] on the less tangible and measurable aspects: on informal interactions and on values such as democracy, equity, community and responsibility. It uses metaphors such as 'the spirit of administration', 'departmental mindset', and 'the human face of bureaucracy'. (Gregory, 2001, 235, italics added)

Reviewing New Zealand's public management reforms on a macro level, Gregory $(2001,236)$ asserts that public choice theory is incongruent with a collective interest and is unable to cope with '(organic) uncertainty and ambiguity'. He argues, for example, that the contractual nature of senior public sector management has contributed to an environment where 'the chief casualty is trust' (244). New Zealand's egalitarian socioeconomic culture does not sit well with the 'neo-liberal social and economic policy reforms' $(247)$. In a subsequent text, Gregory $(2003,96)$ revisits this theme, making the case that the reforms have brought 'less transparency, less trust and increasing inequality. These observations strike a chord with the authors in terms of a professional vision of management and society and provide a useful context in which to explore action learning set comments.

\section{Action set perceptions of workplace purpose}

Analysis of action set contributions suggests a spiritual interpretation of the workplace, connecting to notions of purpose and significance. Fulop and Rifkin (2004) examine management knowledge and reflective learning in the work of Argyris and Schön(1974) and Senge (1990). Fulop and Rifkin propose that these writers are following Bateson's (1975) organic systems thinking, giving rise to experimenting with 'traditions of non-Western cultures ... including storytelling and spiritual experiences' (Fulop and Rifkin 2004, 22). The authors put forward the notion that action set reflections constitute storytelling. Spirituality in the workplace is expressed by characteristics such as valued work, development of workers' capacities, collegial relationships, empowering management, dependable and unambiguous leadership and opportunity for self-management evidence of a 'workplace that inspires creativity and contribution' (Fawcett et al. 2008, 420). 
Notwithstanding qualities of 'creativity' in the district health board environment, contrasting perceptions of artificial organizational change were identified in action set exploration of workplace purpose. Organizational change was seen as a significant struggle, especially where it is extensive and the vision for the organisation is not clear. Images of 'machinery' and 'engineering' exemplified in business process 'reengineering' (Attwood et al. 2003, 21) are at the opposite end of the spectrum from organic approaches to management.

Table 1. Action set evaluations of change management decision making.

\begin{tabular}{|c|c|}
\hline Action set comments & Values/perceptions articulated \\
\hline $\begin{array}{l}\text { 'Things being put on hold while waiting for a new } \\
\text { manager with the uncertainty of what direction } \\
\text { they would take.' }\end{array}$ & $\begin{array}{l}\text { - Artificiality of 'top down' organizational } \\
\text { interventions. } \\
\text { - Direction subject to managerial decisions } \\
\text { perceived as arbitrary. } \\
\text { - 'Uncertainty' predicated on mechanistic } \\
\text { thinking. }\end{array}$ \\
\hline $\begin{array}{l}\text { 'Harm to a team that included social work when } \\
\text { they were reorganised into a larger grouping.' }\end{array}$ & $\begin{array}{l}\text { - Organization's managerial decisions executed } \\
\text { without organic connections with affected staff. } \\
\text { Management of change processes using data } \\
\text { driven logic. } \\
\text { - Harm results when rationalisation occurs without } \\
\text { regard for human connections. }\end{array}$ \\
\hline
\end{tabular}

A second set of comments expressing these action set observations of change management decision making are presented in Table 1. Implications of these perceptions are briefly discussed.

Professional leaders value holistic organizational relationships and are likely to interact with workers in a way designed to counter 'uncertainty', 'harm' and dysfunction in the workplace. The notion of disharmony disturbing natural equilibrium represents an organic image of work in which the 'ideal self drives the personal vision which ...drives sustainable change' (Boyatzis and Akrivou, 2006, 635). Furthermore:

Collective, shared desired images of the future, shared hope, and shared sense of a group's identity and distinctiveness ... become the shared vision that drives sustainable, intentional at ...other levels of social and human organization. (635)

Organic leadership of the nature and quality described by Boyatzis and Akrivou (2006) is mediated through the exemplary leadership practices (Kouzes and Posner, 2007): 'encourage the heart; enable others to act; challenge the process; inspire a shared vision; model the way'. Action set comments (see Figs 1-5) constitute the professional leaders' ideas of how influence is exercised organically and illustrate Boyatzis' $(2006,607)$ conceptualization of organizational change:

The idea of smooth, continuous change does not fit with ...reality ...It requires the use of complexity theory to understand the process of change. ... Concepts from complexity theory ... helps to explain sustainable change at all levels of human and social organization.

\section{Action learning applications}

Action learning as a discipline was cited in the introduction as Revans' $(1982,724)$ seminal definition of the field as a person 'learning from [his] actions [I]' as an ongoing participant with professional colleagues [WE]; and through professional and academic dissemination shared that learning with 'the wider world [THEY].' The lead author's collegial professional leaders' focus group setting enabled exploration of concepts and images. The thoughts and actions of this group 
provide the cultural context in which the lead author has functioned for over 10 years in the Auckland DHB as mental health professional social work leader, located in hierarchical terms at Level 3 (see Figure 6). Action set discussion and ideas, their subsequent dissemination in the organization and publication to a wider audience represent action learning. His influence was essentially organic rather than positional. The presence at Clinical Board Level 1 of the director of allied health in this organization raised the lead author's potential to advance the values espoused by professional leadership in the Auckland DHB. Social work is recognized as an allied health occupation, numerically the largest group in that sector. The advent of clinical governance with potential for organic professional influences not dependent on formal position is a critical element in resolving the tensions and connections between emergent leadership and formal organization structure power and authority. As indicated earlier, exploration of the clinical governance model awaits treatment in a future paper.

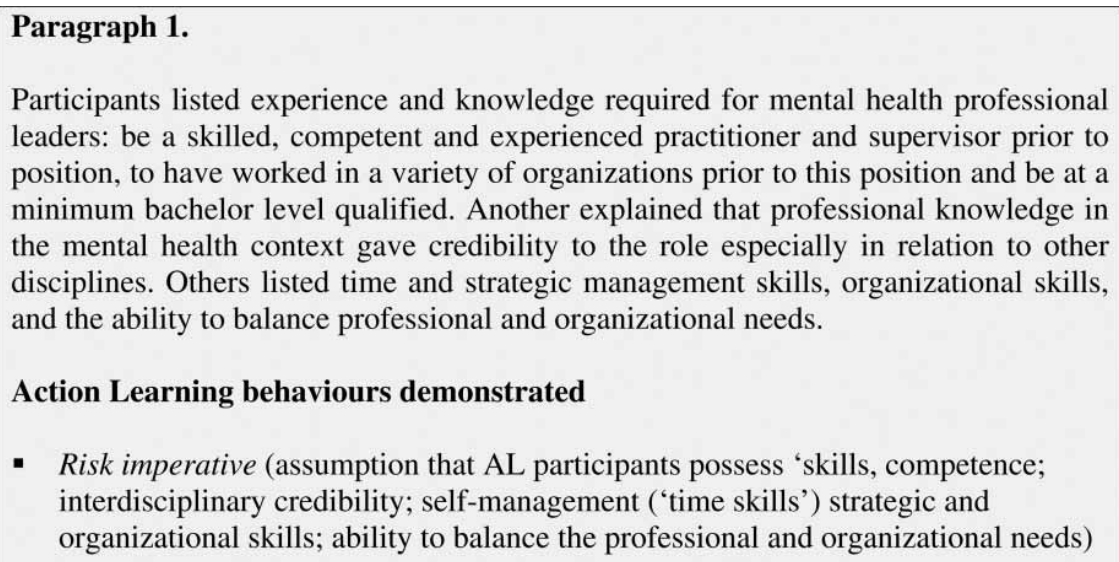

- Risk imperative (assumption that AL participants possess 'skills, competence; interdisciplinary credibility; self-management ('time skills') strategic and organizational skills; ability to balance the professional and organizational needs)

Figure 1. Paragraph 1: model the way.

\section{Emergent leadership}

This paper suggests that the lead author's emergent leadership role is understood by organic images of how organizations function. Models of organizational design, functioning and culture in respect of professional leadership in the health provider setting of this study are arguably better understood from biological metaphors than a bureaucratic Weberian construct. Tensions exist between scientific measurement of outputs - characteristic of managerialist reforms - and the sociocultural anthropological and social work qualities of management. The latter incorporate values of personal aspirations, interpersonal relationships and social groups: in essence, 'moral' systems of meaning. The lead author's ability to influence MHS is better understood in these organic terms. 


\begin{abstract}
Paragraph 2.
One participant noted a commitment to standards of practice, another acknowledged the significance of the professional leader as role model, another that leadership required adaptability, patience and lateral thinking. Competence in research skills and information processing was noted. Aspiration to qualities of open, honest, nonjudgmental, inclusive style of leadership was espoused. Some participants wanted to develop: their training/further education, excellent facilitation skills and better stress management. Another participant thought it important to understand and demonstrate outcomes for Māori development.

\section{Action Learning behaviours demonstrated}

- Risk imperative: assumptions that AL participants are role models; that they were adaptable, patient and lateral thinkers; that they were competent researchers and information processors; that they aspired to open, honest, non-judgmental, inclusive leadership, excellent facilitation.

- $L=P+Q$ : 'questioning insight' by aspiration to an inclusive leadership style at variance with the prevailing managerialist model of 2001.
\end{abstract}

Figure 2. Paragraph 2: model the way.

\title{
Paragraph 1.
}

Mental health professional leaders demonstrated advocacy and change agent skills on behalf of mental health, identifying key leadership qualities as ability to advocate and apply ecological leverage through system strengths and resources to articulate a professional role. Good situational knowledge enabled practise of qualities they valued. No shortage of challenges as a mental health professional leader of social workers was evident.

\section{Action learning behaviours demonstrated}

- $Q$ as creating a learning community of shared values: learning to be change agents.

Figure 3. Paragraph 1: challenge the process.

Paragraph 2.

Aspects of challenging the process were discussed, with some participants identifying positive influence in their organisation with support from key people such as the clinical director. Effective leadership included self-invitation to meetings to keep informed, connected with clarity of role and objective: a right to represent professionals and being self reflective as a leader.

\section{Action learning behaviours demonstrated}

- $Q$ as willingness to challenge the process: creating a leadership ethos by proactive initiatives, e.g. self-invitation to meetings.

- $Q$ as creating a learning community of shared values: discussing actions in the safety of the learning set.

Figure 4. Paragraph 2: challenge the process. 


\section{Complex adaptive change management model}

A 'complex adaptive' change management model characterises the case study. Olson and Eoyang $(2001,9)$ propose that a 'complex adaptive systems behave[s] according to three key principles: order is emergent as opposed to hierarchical; the system's history is irreversible; the system's future is often unpredictable'. Olsen and Eoyang assert that most change agents introduce words like restructuring, vision, leadership, and creativity but work within machine-like structures that have no capacity for fundamental transformation (Olson and Eoyang, 2001, 3-4). In their treatment of complexity, which enjoys self-evident conceptual connections with Morgan's (1997) ideas, Lewin and Regine $(2001,24,27)$ draw the biological parallel of the embryo's human development process to illustrate complexity 'science' in organizations. 'This [biological] process', they observe, 'is still a deep mystery ... it is not a simple mechanistic process; it is highly complex, and involves rich networks of interactions. Complexity theory focuses on the nature of interactions among individual "agents" in a complex adaptive system".

\section{Paragraphs 3 and 4:}

Assuming a new leadership role was seen as a difficult experience. Some had come into their role after a gap from the previous incumbent, which seemed to make it harder to gain traction. Initiating meetings for information and dealing with reactions to new ideas was needed. Assessing the quality of core functions, e.g. professional supervision required time.

Some respondents saw organizational change as a significant struggle, especially where the vision and direction for the organization is not clear and is uncertain. Potential harm to a team that included social workers reorganised into a larger grouping was identified. Pay disparities between social workers because of differential interpretations of salary scales by managers in different units was raised in conjunction with recruitment problems.

\section{Action learning behaviours demonstrated}

- $Q$ as producing creative, productive work: new leadership style is a difficult experience; reactions to new ideas; organizational change as a significant struggle; potential harm to social workers.

Figure 5. Paragraph 3: challenge the process. 


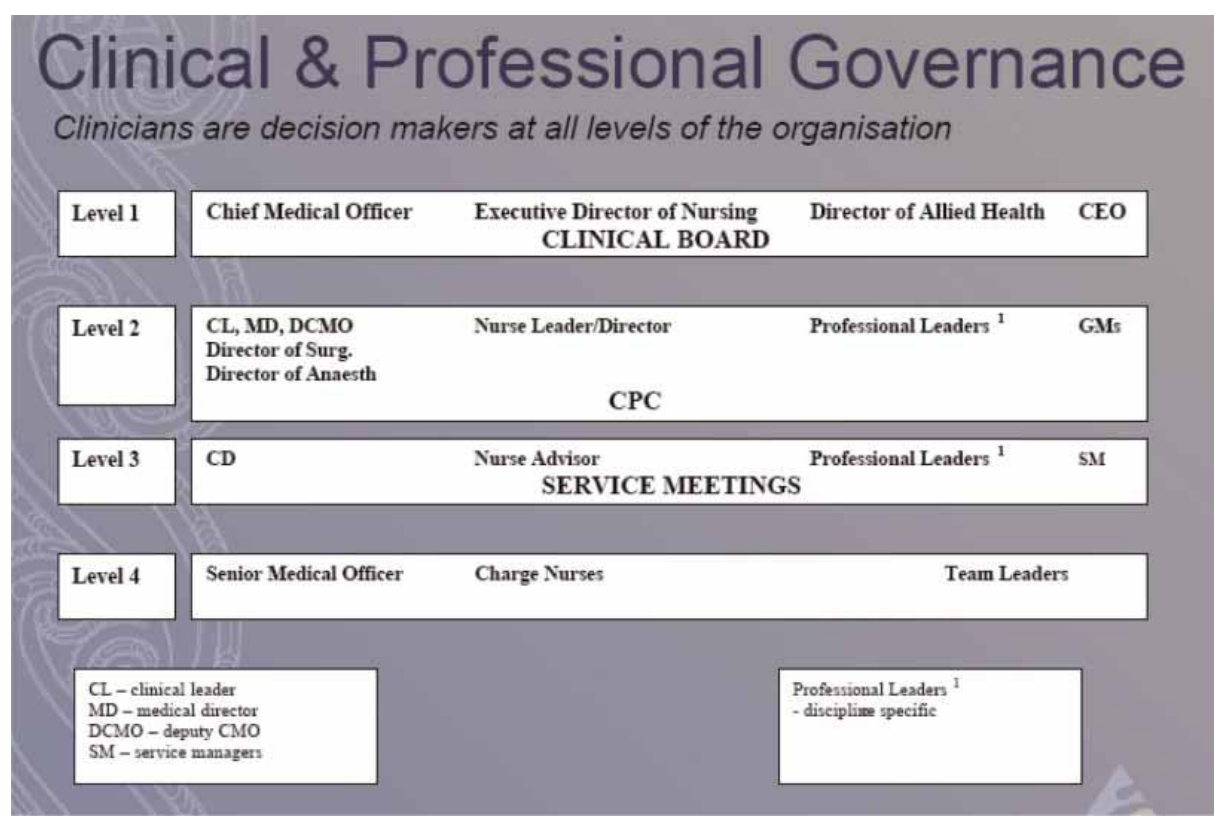

Figure 6. Clinical and professional governance in the Auckland District Health Board. Source: Auckland District Health Board, 2007; @2007, reproduced with kind permission of Auckland District Health Board.

Such interactions with managers, colleagues and the wider professional community describe the lead author's modus operandi in this case study. Professional social workers understand the web of living relationships in which their clients function. Applying that understanding to organizational contexts such as Auckland DHB is a natural progression of professional practice. Change is not seen as a managerial template, but as the natural consequence of engaging hearts and minds in an exemplary leadership framework. Influence of like minds is far less prescriptive than the typical top down change management model (e.g., Kotter, 1995). The authors propose that the tensions that NPM created in Auckland DHB were mediated through an organic approach to the change task and by the informal networks of professional leaders humanized the process.

\section{Conclusion}

The narrative in this action learning case study evokes contradictory images of leaders exercising organic influence in the midst of an ostensibly managerially-driven change process. Findings of the project suggest a tension between cognitive evaluations by participants, represented by the quantitative questionnaire responses, and qualitative responses, represented by action learning set comments. Four of nine questionnaire respondents, the largest block, saw the future in negative terms.

The richer data typically emanating from qualitative research paints a different picture of realistic hope, which, while recognizing the potentially constricting organizational context, articulated enthusiasm, collegial support and concern for dysfunction in the organization - or organism (de Geus 1999). Further exploration of the integration of emergent leadership and organic change with the clinical governance model of health provider organizations in New Zealand, modeled on the UK approaches, is suggested by the authors. 


\section{References}

Argyris, M., and D. Schön. 1974. Theory in practice: Increasing professional effectiveness. San Francisco: Jossey-Bass.

Attwood, M., M. Pedler, S. Pritchard, and D. Wilkinson. 2003. Leading change: A guide to whole systems working. Bristol: Policy Press.

Auckland District Health Board. 2007. Clinical and professional governance. Auckland: Auckland District Health Board.

Bass, B., and B. Avolio. 1993. Transformational leadership and organizational culture. Public Administration Quarterly 17, no. 1: 112-21.

Bateson, G. 1975. Steps to an ecology of mind. New York: Ballantine.

Bennis, W., and B. Nanus. 1985. Leaders: The strategies fortaking charge. New York: Harper and Row.

Blanchard, K., P. Zigarmi, and R. Nelson. 1993. Situational leadership after 25 years: A retrospective. Journal of Leadership Studies 1, no. 1: 22-36.

Boyatzis, R., and K. Akrivou. 2006. The ideal self as the driver of intentional change. Journal of Management Development 25, no. 7: 624-42.

Boyatzis, R.E. 2006. An overview of intentional change from a complexity perspective. Journal of Management Development 25, no. 7: 607-23.

Burns, J. 1978. Leadership. New York: Harper Collins.

De Geus, A. 1999. The living company: Growth, learning and longevity in business. London: Nicholas Brealey.

Deming, W.E. 1986. Out of the crisis. Cambridge, MA: MIT.

Etzioni, A., ed. 1969. The semi-professions and their organization: Teachers, nurses, social workers. New York: Free Press.

Fawcett, S., J. Brau, G. Rhoads, D. Whitlark, and A. Fawcett. 2008. Spirituality and organizational culture: Cultivating the ABCs of an inspiring workplace. International Journal of Public Administration 31, no. 4: 420-38.

Fulop, L., and W. Rifkin. 2004. Management knowledge and learning. In Management and organization: A critical text, ed. S. Linstead, L. Fulop and S. Lilley, 14-47. Basingstoke/New York: Palgrave Macmillan.

Graham, P., ed. 1995. Mary Parker Follett - prophet of management: A celebration of writings from the 1920s. Boston, MA: Harvard Business School Press.

Gregory, R. 2001. Transforming governmental culture: A sceptical view of new public management. In New public management: The transformation of ideas and practice, ed. T. Christensen and P. Lægreid, 231-58. Aldershot: Ashgate Publishing.

Gregory, R. 2003. New Zealand - the end of egalitarianism? In Reward for high public office: Asian and Pacific-rim states, ed. C. Hood, B. Peters with G. Lee, 88-104. London, New York: Routledge.

Hussey, J., and R. Hussey. 1997. Business research: A practical guide for undergraduate and postgraduate students. Basingstoke: Macmillan.

Jarvis, P. 1995. Adult education and lifelong learning: Theory and practice. 2nd ed. London/New York: Routledge.

Jarvis, P. 2004. Adult education and lifelong learning: Theory and practice. 3rd ed. London/New York: RoutledgeFalmer.

Kolb, D. 1984. Experiential learning: Experience as the source of learning and development. Englewood Cliffs, NJ: Prentice-Hall.

Kotter, J. 1995. Leading change: Why transformation efforts fail. Harvard Business Review 73, no. 2: 59-67.

Kouzes, J., and B. Posner. 1995. The leadership challenge. 2nd ed. San Francisco: Jossey-Bass.

Kouzes, J., and B. Posner. 2007. The leadership challenge. 4th ed. San Francisco: Jossey-Bass.

Lewin, R., and B. Regine. 2001. Weaving complexity and business: Engaging the soul at work. New York/ London: Texere. 
Matthewson, P. 2007. Professional leadership in mental health social work: An examination of a professional leadership role in the mental health division of a New Zealand district health board. Social Work Review 19, no. 3: 38-47.

Mintzberg, H. 1989. Mintzberg on management: Inside our strange world of organisations. Chicago: Free Press.

Mizrahi, T., and C. Berger. 2001. Effect of a changing health care environment on social work leaders: Obstacles and opportunities in hospital social work. Social Work 46, no. 2: 170-82.

Mueller, J., and P. Neads. 2005. Allied health and organisational structure: Massaging the organisation to facilitate outcomes. New Zealand Journal of Physiotherapy 33, no. 2: 48-54.

Morgan, G. 1997. Images of organization. Thousand Oaks, CA: Sage.

Morris, J. 1991. Minding our Ps and Qs. In Action learning in practice. ed. M. Pedler, 2nd ed., 71-80. Aldershot: Gower.

Moullin, M. 2002. Delivering excellence in health and social care: Quality, excellence and performance measurement. Maidenhead/New York: Open University Press/McGraw-Hill Education.

Northouse, P. 2007. Leadership: Theory and practice. 4th ed. Thousand Oaks, CA: Sage.

Olson, E., and G. Eoyang. 2001. Facilitating organization change: Lessons from complexity science. San Francisco: Jossey-Bass/Pfeiffer.

Payne, M.S. 1997. The social construction of social work theory. In Modern social work theory, 2nd ed., 1-25. Basingstoke: Macmillan.

Payne, S.C., S.S. Culbertson, W.R. Boswell, and E.J. Barger. 2008. Newcomer psychological contracts and employee socialization activities: Does perceived balance in obligations matter? Journal of Vocational Behavior 73, no. 3: 465-72.

Pedler, M. 2004. Editorial. Action Learning 1, no. 1: 3-7.

Pedler, M. 2008. Action learning for managers. Aldershot: Ashgate.

Pedler, M., and C. Abbott. 2008. Am I doing it right? Facilitating action learning for service improvement. Leadership in Health Services 21, no. 3: 185-99.

Rank, M., and W. Hutchison. 2000. An analysis of leadership within the social work profession. Journal of Social Work Education 36, no. 3: 487-502.

Revans, R. 1982. The origins and growth of action learning. Bromley: Chartwell-Bratt.

Revans, R. 1991. Action learning: Its origins and nature. In Action learning in practice, ed. M. Pedler, 2nd ed., 3-15. Aldershot: Gower.

Revans, R. 1998. ABC of action learning. London: Lemnos \& Crane.

Schön, D.A. 1991. The reflective practitioner: How professionals think in action. Aldershot: Ashgate.

Senge, P. 1990. The fifth discipline: The art and practice of the learning organization. New York: Doubleday/Currency.

Stacey, R., and D. Griffin. 2008. Introduction. In Complexity and the experience of values, conflict and compromise in organizations, ed. R. Stacey and D. Griffin, 1-19. Abingdon/New York: Routledge.

Te Whaiti Nui-a-Toi. 2001. Tipu Ake ki te Ora. http://www.tipuake.org.nz/tipu_life_cycle.htm

Thorburn, J., D. McNabb, and D. Rook. 2007. One year of professional supervisors in mental health services: A review of progress. Auckland: Auckland DHB.

Trehan, K., and M. Pedler. 2009. Animating critical action learning: Process-based leadership and management development. Action Learning 6, no. 1: 35-49.

Uhl-Bien, M., and R. Marion. 2008. Complexity leadership. Charlotte, NC: Information Age.

Wenger, E., R. McDermott, and W. Snyder. 2002. Cultivating communitiesof practice: A guide to managing knowledge. Boston, MA: Harvard Business School Press.

Woodward, P. 2001. Mental health and social work. In New Zealand social work: Contexts and practice. ed. M. Connolly, 168-80. Auckland, NZ: Oxford University Press.

Yuk1, G. 2010. Leadership in organizations. 7th ed. Upper Saddle River, NJ: Prentice Hall. 